\title{
вмJ Global Health Health system modelling research: towards a whole-health-system perspective for identifying good value for money investments in health system strengthening
}

Stéphane Verguet, ${ }^{\oplus 1}$ Isabelle Feldhaus, ${ }^{1}$ Xiaoxiao Jiang Kwete, ${ }^{1}$ Anwer Aqil, ${ }^{2}$ Rifat Atun, ${ }^{1}$ David Bishai, ${ }^{3}$ Michele Cecchini, ${ }^{4}$ Augusto Afonso Guerra Junior, ${ }^{5}$ Mahlet Kifle Habtemariam, ${ }^{1,6}$ Abdulrahman Jbaily, ${ }^{1}$ Ozge Karanfil, ${ }^{1,7}$ Margaret E Kruk, ${ }^{1}$ Sebastien Haneuse, ${ }^{8}$ Ole Frithjof Norheim, ${ }^{1,9}$ Peter C Smith, ${ }^{10,11}$ Mieraf Taddesse Tolla, ${ }^{1}$ Solomon Zewdu, ${ }^{12}$ Jesse Bump ${ }^{1}$

To cite: Verguet S, Feldhaus I, Jiang Kwete $\mathrm{X}$, et al. Health system modelling research: towards a whole-health-system perspective for identifying good value for money investments in health system strengthening. BMJ Glob Health 2019;4:e001311. doi:10.1136/ bmjgh-2018-001311

Handling editor Seye Abimbola

Received 15 November 2018 Revised 8 February 2019 Accepted 15 February 2019

\section{Check for updates}

(c) Author(s) (or their employer(s)) 2019. Re-use permitted under CC BY-NC. No commercial re-use. See rights and permissions. Published by BMJ.

For numbered affiliations see end of article.

Correspondence to Professor Stéphane Verguet verguet@hsph.harvard.edu

\section{ABSTRACT}

Global health research has typically focused on single diseases, and most economic evaluation research to date has analysed technical health interventions to identify 'best buys'. New approaches in the conduct of economic evaluations are needed to help policymakers in choosing what may be good value (ie, greater health, distribution of health, or financial risk protection) for money (ie, per budget expenditure) investments for health system strengthening (HSS) that tend to be programmatic. We posit that these economic evaluations of HSS interventions will require developing new analytic models of health systems which recognise the dynamic connections between the different components of the health system, characterise the type and interlinks of the system's delivery platforms; and acknowledge the multiple constraints both within and outside the health sector which limit the system's capacity to efficiently attain its objectives. We describe priority health system modelling research areas to conduct economic evaluation of HSS interventions and ultimately identify good value for money investments in HSS

\section{INTRODUCTION}

Non-communicable diseases (NCDs), which often manifest with multiple conditions within the same patient, expose some of the inadequacies of health systems unprepared for the rapid epidemiological transition from communicable diseases to NCDs. ${ }^{12}$ Governments, international organisations and donors worldwide are concerned about rising costs of healthcare, coupled with inadequate performance of national health systems. Moreover, the rise in NCD burden has driven cost increases as more expensive

\section{Summary box}

Global health research has typically focused on single diseases, and most economic evaluation research has analysed technical health interventions to identify 'best buys'.

- New approaches in the conduct of economic evaluations are needed to help policymakers in choosing what may be good value (ie, greater health, distribution of health, or financial risk protection) for money (ie, per budget expenditure) investments for health system strengthening (HSS).

- Economic evaluations of HSS interventions will require developing new analytic models of health systems which recognise the dynamic connections between the different components of the health system.

- We describe priority health system modelling research areas to conduct economic evaluation of HSS interventions and ultimately identify good value for money investments in HSS.

therapies are needed for longer durations of treatment. Hence, many policymakers are concerned about improving efficiency and effectiveness of health systems.

Contrary to these looming trends, however, global health research has typically focused on single diseases, on vertical programmes in isolation and on single technical interventions (eg, introduction of new technologies like vaccines or drugs). ${ }^{3}$ As a case in point, most economic evaluations to date, including cost-effectiveness analysis research that explores both technical and allocative efficiency, have analysed single health interventions and thus 
operationalised the computation of total health gains (eg, total deaths averted or disability-adjusted life years averted) per total expenditure on specific interventions to identify 'best buys'.

New approaches in the conduct of economic evaluations are needed to help policymakers choose what may be good value (ie, greater health, distribution of health, or financial risk protection) for money (ie, per budget expenditure) investments for health system strengthening (HSS) that tend to be programmatic rather than single technical interventions. As a result, HSS interventions are more difficult to evaluate. HSS interventions that warrant evaluation include, for example, workforce training and deployment, pharmaceutical procurement and supply chain management, organisational management, cross-sectoral coordination and community-based convening. We posit that these new approaches must first consider system-wide delivery platforms (eg, district public health departments, health posts, community health workers, clinics) and operational elements (eg, community health boards, data information systems, supply chains) as units of analysis, in place of disease-focused interventions, to improve one particular platform (technical efficiency) or ration across platforms (allocative efficiency). Second, they should capture the dynamic interactions between the main interdependent components of health systems, specifically financing, delivery, individual behaviour and community decision-making, accounting for feedbacks, adaptations and synergies. Third, they have to maintain, as central outcomes of interest, the major objectives-what we call 'value' in this paper-of health systems commonly agreed on, ${ }^{5-7}$ notably: improving health and its distribution at the level of the population, providing financial risk protection efficiently (accounting for budget constraints), ${ }^{8}$ and increasing the satisfaction of citizens, while potentially acknowledging the positive implications that a healthier population may have on healthcare and the broader economy. ${ }^{9}$ Fourth, they should clearly articulate the comparators and counterfactuals pertaining to HSS interventions: whether an HSS intervention (eg, workforce training) is compared with another HSS intervention (eg, improving the drug supply chain) or with the status quo. Last, evaluation of multiple outcomes (eg, health, distribution of health, financial risk protection) raises the question of how to weigh each of these outcomes against one another and whether to produce an aggregated summary value or to maintain a dashboard of outcomes.

Collectively, these considerations imply that economic evaluations of HSS interventions will require developing new analytic models of health systems which: (1) acknowledge the dynamic connections between the different components of the health system and the policy levers acting on them, as well as characterise the type and interlinks of the system's delivery platforms-that is, quantify the dynamic interactions between

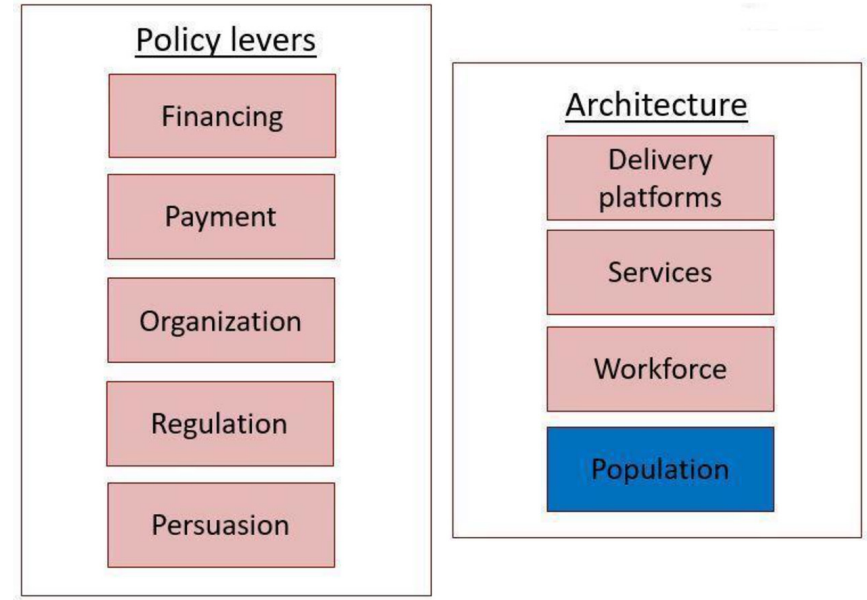

Figure 1 Description of the health system elements and policy levers which are subject to dynamic interactions and constraints and are amenable to health system modelling. Adapted from Roberts, Hsiao, Berman and Reich (2008).

major health system components and (2) recognise the multiple constraints both within and outside the health sector which limit the system's capacity to efficiently attain its objectives-that is, incorporate the constraints limiting the delivery of health to populations.

In illustrating such priority health system modelling (HSM) research areas for conducting economic evaluations of HSS interventions, we keep in mind the following major analytical question: how to identify good value (ie, greater health, distribution of health, or financial risk protection) for money (ie, per budget expenditure) investments in HSS?

\section{PRIORITY HSM RESEARCH AREAS Quantifying the dynamic interactions between major health system components}

Beyond technical interventions, the WHO has defined six components of health systems ${ }^{10}$ and the World Bank's flagship course on health system strengthening and sustainable financing has highlighted five control knobs or policy levers (financing, payment, organisation, regulation and persuasion) to analyse when pursuing health sector reform (figure 1). ${ }^{6}$ It is important to recognise, however, that health system actors and the population interact within rapidly changing environments that either physically (eg, road networks), socially (eg, education and socioeconomic status) or politically (eg, institutions) determine health promotion and care. These, in turn, play an important role in determining quantitative and dynamic relationships between health system components, policy levers and the population. ${ }^{11}$ An example of such relationships is the procurement and delivery of medicines, which, from manufacturers to clinics, evolve continuously over time in response to the population demand and behaviour and drug stock-outs, and are characterised by ever-changing feedbacks to suppliers, which can 
be enhanced depending on the organisational and financing capacity that is embedded in the broader policy environment (eg, national patent policy, regulatory capacity of generic drugs).

In this respect, HSM research can use systems thinking, ${ }^{12}$ a qualitative stepping stone towards modelling, to represent the health system as a complex adaptive system. Using systems thinking will imply synthesising the intrinsic features including control loops (dynamic interactions resulting from policy levers) and feedbacks (nature and quantification of these interactions). Drawing from other disciplines like operations research, management and behavioural sciences and using system dynamics, ${ }^{13} 14$ discrete-event simulations analysing queuing processes ${ }^{15} 16$ and agentbased modelling materialising adaptive systems ${ }^{15} 17$ sampling from large datasets, we can develop dynamic simulation models (both qualitative and quantitative in nature) of health systems that are able to predict the effect of acting on a given policy lever (figure 1).
For instance, removing fee-for-service for selected healthcare services would initially increase population demand, modulated by individuals' quality of care perception, which, contingent on external constraints, will drive the drug supply and workforce deployment, further requiring additional funds and eventually leading to adjusting the initial population demand, stabilising it at a different level. Evaluating this requires the use of a simulation model that includes such dynamics and their associated costs and benefits. However, HSM research will imply specific challenges which analysts will need to address (table 1).

\section{Incorporating the constraints limiting the delivery of health to the population}

National health systems rely on a range of physical entities including delivery platforms (eg, hospitals, clinics, district public health offices), the arrangement of prevention and treatment services and the deployed workforce (eg, doctors, nurses, community health workers). ${ }^{18}$

Table 1 Possible challenges of and approaches to health system modelling research

\begin{tabular}{ll}
\hline Challenge & Description \\
\hline Formulation of model & The model should capture the dynamic \\
interactions between the main components of & the health system and acknowledge constraints. \\
& Deciding on which components and constraints \\
& to include depends on what is most relevant to \\
& the problem under study and data availability.
\end{tabular}

\section{Potential approach}

Assembling all available datasets before model conceptualisation enables modellers to recognise what should be included in the model.

- Examples of datasets include: household surveys for population health and socioeconomic characteristics, geographic information systems for facility locations and human resource allocations, health management information systems for drug stocks and patient visits.

Parametrisation of $\quad$ The model can consist of many parameters that need to be identified.

- In addition to the difficulty of dealing with a large parameter space, some parameters are qualitative in nature (eg, skills of workforce, quality of education, political feasibility). datasets from multiple sources such as: Demographic and Health Surveys, Multiple Indicator Cluster Surveys, Service Provision Assessment, Service Availability and Readiness Assessment, National Health Accounts, World Development Indicators,

\begin{tabular}{|c|c|c|}
\hline Validation of model & $\begin{array}{l}\text { Multiple distinct datasets should be used to } \\
\text { validate the model. }\end{array}$ & $\begin{array}{l}\text { Multiple intermediate indicators and outputs (eg, } \\
\text { coverage of health services) along with outcomes (eg } \\
\text { disease incidence) should be monitored. }\end{array}$ \\
\hline Large simulations & $\begin{array}{l}\text { The model can consist of many compartments } \\
\text { and routines depending on both space and } \\
\text { time (eg, location of health facilities and road } \\
\text { networks relative to population distribution, drug } \\
\text { supply chain) which requires the use of large } \\
\text { simulations. }\end{array}$ & $\begin{array}{l}\text { High performance computing and parallel } \\
\text { programming can be used to perform such required } \\
\text { large simulations. }\end{array}$ \\
\hline $\begin{array}{l}\text { Presentation of model } \\
\text { results }\end{array}$ & $\begin{array}{l}\text { The model can consist of multiple outcomes to } \\
\text { be evaluated. } \\
\text { The model should allow a clear comparison of } \\
\text { impact between HSS interventions. }\end{array}$ & $\begin{array}{l}\text { Present model findings with the use of dashboards } \\
\text { displaying all possible outcomes or with aggregating } \\
\text { outcomes using weights. } \\
\text { Define the limits of the impact of HSS interventions } \\
\text { and the status quo. }\end{array}$ \\
\hline Data gaps & $\begin{array}{l}\text { A large data repository is preferable to build a } \\
\text { complete model, yet data gaps are inevitable. }\end{array}$ & $\begin{array}{l}\text { Once gaps are identified, data collection can be } \\
\text { pursued to improve future versions of the model. }\end{array}$ \\
\hline
\end{tabular}
Global Burden of Disease Study.

- As for qualitative features, numerical values may be assigned to different categories of a certain variable (eg, for rating workforce skills) and a variety of scenario analyses can be conducted.

Multiple intermediate indicators and outputs (eg, coverage of health services) along with outcomes (eg programming can be used to perform such required supply chain) which requires the use of large The model can consist of multiple outcomes to displaying all possible outcomes or with aggregating outcomes using weights.

the impact pursued to improve future versions of the model. 
This physical architecture dictates the interconnections between platforms, services, workforce and the population, which cannot function in isolation from each other; it also defines the limits of the health system capabilities. Notably, health services can be interdependent through a commonly shared delivery platform in three ways: ${ }^{19}$ through the quality of care of an existing platform (eg, quality is improved for the whole platform, such as an operating room providing a range of services), through the specific constraints underpinning an existing platform (eg, limited medical equipment and personnel) and through the constitution of new platforms (eg, new clinics) jointly bundling these health services. Recognising this, it is clear that the eventual impact of any given policy lever will be constrained by the underlying architecture of the health system including its policy environment (figure 1).

Importantly, HSM research must describe health systems through the types and in-between links of delivery platforms, services provided and workforce deployed. First, this description involves classifying and quantifying the health system infrastructure (eg, services, platforms, facilities), the distribution and allocation of human resources (eg, health vs non-health workforce) and the contextual networks impacting health delivery (eg, roads, population locations). Second, it suggests that it will be important to measure and assess the financial (eg, availability of public vs private funds) and leadership/political (eg, civil vs governmental stakeholders influencing policymaking and implementation) dimensions that constrain the implementation of HSS interventions. ${ }^{18}$ For instance, system dynamic methods can be used to capture complex systems and trade-offs between cure and prevention interventions and the impact of adapted policies. ${ }^{20}$ Politics can also serve as a driver of reform and implementation. Thus, political analysis and modelling can be useful on their own, ${ }^{21}$ especially to understand and incorporate political constraints.

Finally, pursuing such a detailed description of health systems amenable to modelling should be tied to using multiple sources of data (both health and non-health). For example, geographic information systems can procure detailed maps of settings including buildings, and big data from social media can generate behavioural information; linking GPS coordinates of roads, villages and facilities and management information systems on patient visits and drug stocks can enable diagnosis of supply and delivery bottlenecks (table 1).

\section{CONCLUSION}

HSM research should model the complex dynamics of health systems and ultimately guide a novel economic evaluation framework for analysing HSS interventions. To achieve this, HSM research can use dynamic mathematical models to predict the value for money of HSS interventions and policy changes.
The HSS interventions to study would draw from the five policy levers detailed by Roberts and colleagues, ${ }^{6}$ whose spheres of action and eventual impact would be quantitatively determined by the underlying physical architecture of the health system and the dynamic interactions between its components. A possible element of these analyses could be to anchor health system models within an 'Input-Output' framework, where the policy levers (eg, financing, payment, organisation, regulation, persuasion) include inputs and processes of how inputs are used, where health system objectives (eg, level and distribution of health, financial risk protection) are considered outcomes and where all available evidence is used to appropriately associate the inputs, outputs and outcomes.

Finally, HSM research to identify good value for money investments in HSS would have implications for the broader global health community. National governments, donors and the research community would need to collect system-wide indicators (eg, quality ${ }^{22}$ and financial risk protection ${ }^{23}$ indicators) rather than solely disease-specific indicators. Rather than single vertical programmes, they should also economically evaluate HSS programmes, including their costs and impact on health, and understanding the role of the health system components in that impact.

\section{Author affiliations}

${ }^{1}$ Department of Global Health and Population, Harvard T.H. Chan School of Public Health, Boston, Massachusetts, USA

${ }^{2}$ Office of Health Systems, USAID Bureau for Global Health, Arlington, Virginia, USA

${ }^{3}$ Department of Family and Population Health, Johns Hopkins University Bloomberg School of Public Health, Baltimore, Maryland, USA

${ }^{4} \mathrm{OECD}$, Paris, France

${ }^{5}$ School of Pharmacy, Universidade Federal de Minas Gerais, Belo Horizonte, Brazil ${ }^{6}$ Federal Ministry of Health, Addis Ababa, Ethiopia

${ }^{7}$ College of Administrative Sciences and Economics, Koc Universitesi, Istanbul, Turkey

${ }^{8}$ Department of Biostatistics, Harvard T.H. Chan School of Public Health, Boston, Massachusetts, USA

${ }^{9}$ Department of Global Public Health and Primary Care, University of Bergen, Bergen, Norway

${ }^{10}$ Imperial College Business School, London, UK

${ }^{11}$ Center for Health Economics, University of York, York, UK

${ }^{12}$ Bill and Melinda Gates Foundation, Global Development, Addis Ababa, Ethiopia

Acknowledgements We thank the Department of Global Health and Population at the Harvard T.H. Chan School of Public Health for funding as well as participants in a meeting at Harvard University held in September 2017. We are grateful to Michael R Reich for useful comments on an earlier version of this paper.

Contributors SV conceived the paper and wrote the first draft of the manuscript with inputs from JB. All authors subsequently reviewed and edited the manuscript, and approved submission to publication.

Disclaimer The opinions expressed and arguments employed herein are solely those of the authors and do not necessarily reflect the official views of their organisational affiliations.

Competing interests None declared.

Patient consent for publication Not required.

Provenance and peer review Not commissioned; externally peer reviewed.

Data sharing statement No additional data are available.

Open access This is an open access article distributed in accordance with the Creative Commons Attribution Non Commercial (CC BY-NC 4.0) license, which 
permits others to distribute, remix, adapt, build upon this work non-commercially, and license their derivative works on different terms, provided the original work is properly cited, appropriate credit is given, any changes made indicated, and the use is non-commercial. See: http://creativecommons.org/licenses/by-nc/4.0/.

\section{REFERENCES}

1. Murray CJL, Barber RM, Foreman KJ, et al. Global, regional, and national disability-adjusted life years (DALYs) for 306 diseases and injuries and healthy life expectancy (HALE) for 188 countries, 1990-2013: quantifying the epidemiological transition. Lancet 2015;386:2145-91.

2. Atun R, Jaffar S, Nishtar S, et al. Improving responsiveness of health systems to non-communicable diseases. Lancet 2013;381:690-7.

3. Jamison DT, Breman JG, Measham AR, et al. Disease control priorities in developing countries. 2nd edn. Washington, DC: The World Bank, 2006.

4. World Health Organization. Choosing interventions that are costeffective. Available: http://www.who.int/choice/en/

5. Murray CJ, Frenk J. A framework for assessing the performance of health systems. Bulletin of the World Health Organization 2000;78:717-31.

6. Roberts MJ, Hsiao W, Berman P, et al. Getting health reform right. Oxford and New York: Oxford University Press, 2008.

7. Papanicolas I, Smith PC. Health system performance comparison: an agenda for policy, information and research. Maidenhead: Open University Press, 2013.

8. Verguet S, Laxminarayan R, Jamison DT. Universal public finance of tuberculosis treatment in India: an extended cost-effectiveness analysis. Health Economics 2015;24:318-32.

9. Prah Ruger J, Jamison DT, Bloom DE, et al. Chapter 15: Health and the Economy. In: Merson M, Black R, Mills A, et al, eds. Global health: diseases, programs, systems, and policies, pp.757-814. 3ro Ed. Jones \& Bartlett Learning, 2012.

10. World Health Organization. Health systems strengthening glossary. Available: http://www.who.int/healthsystems/hss_glossary/en/ index5.html
11. Atun R, Menabde N. Health systems and systems thinking. In: Coker R, Atun R, McKee M, eds. Health systems and the challenge of communicable diseases: experiences from Europe and Latin America. Open University Press, McGraw Hill Education, 2008: $121-40$

12. de Savigny D, Adam T, eds. Systems thinking for health systems strengthening. Geneva: World Health Organization, 2009.

13. Sterman J. Business dynamics: systems thinking and modeling for a complex world. McGraw-Hill, 2000.

14. Chang AY, Ogbuoji O, Atun R, et al. Dynamic modeling approaches to characterize the functioning of health systems: a systematic review of the literature. Social Science \& Medicine 2017;194:160-7.

15. Marshall DA, Burgos-Liz L, IJzerman MJ, et al. Applying dynamic simulation modeling methods in health care delivery ResearchThe simulate checklist: report of the ISPOR simulation modeling emerging good practices Task Force. Value in Health 2015;18:5-16.

16. Siebers PO, Macal CM, Garnett J, et al. Discrete-event simulation is dead, long live agent-based simulation! Journal of Simulation 2010;4:204-10.

17. Gunal MM. A guide for building Hospital simulation models. Health Systems 2012;1:17-25.

18. Smith PC, Yip W. The economics of health system design. Oxford Review of Economic Policy 2016;32:21-40.

19. Hauck K, Morton A, Chalkidou K, et al. How can we evaluate the cost-effectiveness of health system strengthening? A typology and illustrations. Social Science \& Medicine 2019;220:141-9.

20. Bishai D, Paina L, Li Q, et al. Advancing the application of systems thinking in health: why cure crowds out prevention. Health Research Policy and Systems 2014;12.

21. Reich MR. The politics of reforming health policies. Promotion \& Education 2002;9:138-42.

22. Kruk ME, Gage AD, Arsenault C, et al. High-quality health systems in the sustainable development goals era: time for a revolution. The Lancet Global Health 2018;6:e1196-252.

23. World Health Organization and International Bank for Reconstruction and Development/World Bank. Tracking universal health coverage: 2017 global monitoring report. Geneva/Washington, DC: World Health Organization and International Bank for Reconstruction and Development/World Bank, 2017. 